\title{
TRANSFORMING GROWTH FACTOR- $\beta 1$ EXPRESSION IN VARIOUS CONCENTRATIONS OF ADVANCED PLATELET-RICH FIBRIN MODULATING HUMAN DENTAL PULP STEM CELL DIFFERENTIATION
}

\author{
ANGGRAINI MARGONO ${ }^{1 *}$, DINI ASRIANTI ${ }^{1}$, FRIEDA AYU PRIHADINI ${ }^{2}$, INDAH JULIANTO ${ }^{3}$ \\ ${ }^{1}$ Department of Conservative Dentistry, Faculty of Dentistry, Universitas Indonesia, Jakarta, Indonesia. ${ }^{2}$ Conservative Dentistry Residency \\ Program, Faculty of Dentistry, Universitas Indonesia, Jakarta, Indonesia. ${ }^{3}$ Department of Dermatology, Faculty of Medicine, Universitas \\ Sebelas Maret, Surakarta, Central Java, Indonesia. Email: margonodewi@yahoo.com
}

Received: 30 July 2019, Revised: 28 February 2020, Accepted: 01 June 2020

ABSTRACT

Objective: Modification of the speed and time of centrifugation based on the low-speed centrifugation concept for platelet-rich fibrin (PRF) has resulted in a new type of PRF known as advanced PRF (A-PRF). A-PRF can release several types of growth factors (GFs) that participate in the process of differentiation, such as transforming GF- $\beta 1$ (TGF- $\beta 1$ ). The aim of this study was to analyze TGF- $\beta 1$ expression in various concentrations of A-PRF in the differentiation process of human dental pulp stem cells (hDPSCs).

Methods: hDPSC cultures were obtained from those of previous research (ethical approval form has been attached). These hDPSCs were in the $2^{\text {nd }}-3^{\text {rd }}$ passage, and serum starvation was done by reducing fetal bovine serum (FBS) levels in the hDPSC culture media. A-PRF was obtained using $10 \mathrm{ml}$ blood collected from the cubital vein, which was centrifuged at $1500 \mathrm{rpm}$ for $14 \mathrm{~min}$ and then divided into four concentration groups. TGF- $\beta 1$ expression in 1\%, 5\%, and 25\% A-PRF as well as in 10\% FBS (control) was analyzed by ELISA on day 7.

Results: Although no significant differences were observed in TGF- $\beta 1$ expression between 1\%, 5\%, and 25\% A-PRF, and 10\% FBS, it was observed that the higher the concentration of A-PRF, the greater the TGF- $\beta 1$ expression.

Conclusion: The expression of TGF- $\beta 1$ was consistent with the increase in A-PRF concentration. The highest TGF- $\beta 1$ expression was detected in $25 \%$ A-PRF among all concentrations in the differentiation process of hDPSCs.

Keywords: Advanced platelet-rich fibrin, Transforming growth factor beta 1, Differentiation, Human dental pulp stem cells.

(c) 2020 The Authors. Published by Innovare Academic Sciences Pvt Ltd. This is an open access article under the CC BY license (http://creativecommons. org/licenses/by/4. 0/) DOI: http://dx.doi.org/10.22159/ijap.2020.v12s2.0P-44

\section{INTRODUCTION}

In recent years, regenerative endodontics has presented new possibilities for the treatment of necrotic immature permanent teeth based on the combination and interplay of three key elements required for tissue regeneration, namely, stem cells, bioactive molecules, and scaffolds [1]. The traditional triad of dental stem cells, bioactive signal molecules, and bioactive scaffolds as mentioned above fails to generate a healthy functional tissue. This is due to the fact that regenerated tissue does not completely match the normal healthy functional tissue. Hence, a novel dental bioengineering approach has been suggested consisting of the three classic elements (i.e., dental stem cells, signal molecules, and scaffolds) and two new ones (i.e., stem cell niches and survival factors) $[2,3]$

Platelet concentrates, which are known as bioscaffolds and a reservoir of cytokines, have been used for tissue regeneration in current clinical medicine. Platelet-rich fibrin (PRF), the second generation of platelet concentrates, has drawn more attention because of its simple production process and the presence of natural components without any artificial additives. As a reservoir of abundant cytokines, PRF can promote and modulate cell recruitment, proliferation, and differentiation [1]. Furthermore, a modification of the preparation setting based on the previously described low-speed centrifugation concept (LSCC) is a first step in the reduction of the applied relative centrifugal force (RCF). This step is accompanied by a slight increase in centrifugation time, resulting in the so-called advanced PRF (A-PRF) [4]. A-PRF produces the maximum GF levels compared with PRP [5].
Bioactive molecules are signaling factors or chemical cues that regulate a variety of cellular responses by specific binding to the transmembrane or the intracellular receptors on a target cell. The bone morphogenetic protein (BMP) superfamily of proteins such as BMP-2, BMP-4, BMP-7, and transforming growth factor beta- 1 (TGF- $\beta 1$ ) has been found to modulate cellular functions [2]. TGF- $\beta$ is a signaling molecule that induces cell proliferation, cell differentiation, chemotaxis, and apoptosis in monocytes and epithelial, mesenchymal, and neuronal cells. TGF- $\beta 1$ also plays a role in tooth development and reparative process by regulating and modulating cell proliferation, differentiation, and reparative dentinogenesis. In odontoblasts, TGF- $\beta 1$ exerts a key role in the transcriptional regulation of two non-collagenous proteins, dentin sialophosphoprotein (DSPP), and dentin matrix protein-1 (DMP-1). DSPP is one of the non-collagenous proteins that induces mineralization in the extracellular matrix and cannot be detected in other tissues so that it can be used as a phenotype marker of odontoblast activity [6].

TGF- $\beta 1$ specifically interacts with decorin/biglycan in the dentin, although it increases the expression and secretion of NGF in human dentin pulp cells. NGF induces mineralization and increases the expression of DSPP and DMP-1 [7]. The binding of these signaling molecules leads to the activation of several signaling transduction pathways involved in dentinogenesis, odontoblast differentiation, and inflammatory responses, such as the p38 MAPK, NF- $\kappa \beta$, and Wnt/ $\beta$ catenin signaling pathways [7].

\section{METHODS}

This study was approved by the Ethics Committee of the Dental Faculty, Universitas Indonesia (no. 35/ethical approval/FKGUI/V/2018, no. 
Protocol: 090250218). Human dental pulp stem cell (hDPSC) cultures were obtained from those of previous research. These hDPSCs were in the $2^{\text {nd }}-3^{\text {rd }}$ passage before the serum starvation procedure, and serum starvation was done by reducing fetal bovine serum (FBS) levels till 1\% concentration. hDPSCs were divided into four culture media groups; A-PRF $1 \%, 5 \%$, and $25 \%$, and FBS $10 \%$ (as control) after $24 \mathrm{~h}$ of serum starvation, with each group containing three biological replicates (triplo). Serum starvation procedure was performed according to the previously study [8].

The inclusion criteria for blood collection were healthy donors aged 19-35 years with no smoking and alcohol consumption habits. A certified laboratory assistant collected $10 \mathrm{ml}$ of blood from three donors from the cubital vein. After blood collection, within $<2 \mathrm{~min}$, the samples were centrifuged at $1500 \mathrm{rpm}$ for $14 \mathrm{~min}$, and the A-PRF gel layer was separated from red blood cells. Then, the A-PRF was incubated for $24 \mathrm{~h}$ at $4^{\circ} \mathrm{C}$ to collect the supernatant layer. This supernatant layer was used as a culture medium supplement and diluted to concentrations of $1 \%$, $5 \%$, and $25 \%$ A-PRF.

The osteogenic differentiation media consisted of nutritional media (DMEM-Gibco, Thermo Fisher Scientific Inc., Massachusetts, USA), $50 \mu \mathrm{g} / \mathrm{ml}$ of l-ascorbic acid 2-phosphate, $10 \mathrm{mM}$ of $\beta$-glycerophosphate sodium salt, $10 \mu \mathrm{M}$ of dexamethasone, and antibiotics $(100 \mathrm{mg} / \mathrm{ml}$ streptomycin and $100 \mu / \mathrm{ml}$ penicillin-G). For osteogenic differentiation, four 6-well plates were used in which $1 \times 10^{5}$ cells/well were cultured with complete media until reaching approximately $70 \%$ confluence, followed by incubation at $37^{\circ} \mathrm{C}$ and $5 \% \mathrm{CO}_{2}$ for $24 \mathrm{~h}$. The cells were maintained in the osteogenic differentiation media with different concentrations of A-PRF. Specifically, the gene expression level of TGF- $\beta 1$ was measured using an ELISA reader and analyzed by the Kruskal-Wallis statistical test $(\mathrm{p}<0.05)$.

\section{RESULTS AND DISCUSSION}

Cells were analyzed under an inverted light microscope at $\times 10$ before and after being treated for 7 days, as shown in Fig. 1. It was observed that cells after $24 \mathrm{~h}$ of starvation consisted of only a monolayer compared with other images after 7 days of A-PRF supplementation in the growth media, with the hDSPCs being developed into a multilayer.

As shown in Table 1, the amount of TGF- $\beta 1$ expression produced by hDPSCs treated with different A-PRF concentrations was not significant as assessed by the Kruskal-Wallis test. However, Fig. 2 shows that the highest means value of TGF- $\beta 1$ expression was obtained at $25 \%$ A-PRF $(0.721 \pm 0.191 \mathrm{ng} / \mathrm{ml})$, whereas the least value was obtained at $1 \%$ A-PRF $(0.219 \pm 0.225 \mathrm{ng} / \mathrm{ml})$.
The presence of TGF- $\beta$ expression in the dental pulp tissue suggests its potential role in the regulation of dental pulp cell functions during physiological and pathological processes $[9,10]$. Being a large family of signaling proteins, TGF- $\beta$ is involved in several cellular events, including immune response, chemotaxis, odontoblast differentiation, DPSC proliferation and differentiation, as well as production and secretion of dentin matrix $[10,11]$. Three different isoforms of TGF- $\beta$ have been identified in mammals, TGF- $\beta 1$, TGF- $\beta 2$, and TGF- $\beta 3$, with similar biological activities. In hDPSCs, TGF- $\beta 1$ plays a major role in tooth development and reparative process by regulating and modulating cell proliferation, differentiation, and reparative dentinogenesis by sending signals to the dentin pulp complex and regulating the cellular pathways leading to regeneration $[10,11]$

One of the latest innovations in in vivo tissue engineering applications is the use of platelet concentrates. Two types of such platelet concentrates are available, Platelet-Rich Plasma (PRP) and PRF [12]. Choukroun in the early 2000s focused at developing a second generation platelet concentrate without using anticoagulation factors [4]. In addition, a modification of the preparation setting based on the previously described LSCC is a first step in the reduction of the applied RCF. This step is accompanied by a slight increase in centrifugation time, resulting in the so-called A-PRF [4]. PRF can release several types of GFs, such as PDGF and TGF- $\beta$, which modulate fibroblast proliferation and differentiation through TGF- $\beta$-related mechanisms. The results may have differed because of the individual divergence in platelet count and the time interval between blood sample centrifugation, fibrin membrane collection, and cell culture treatment [13].

Table 1 shows that $1 \%, 5 \%$, and $25 \%$ A-PRF, and 10\% FBS were not significantly different in producing TGF- $\beta 1(\mathrm{p}<0.05)$, although substantially TGF- $\beta 1$ expression in $25 \%$ A-PRF was higher than that in $1 \%$ A-PRF. According to Fig. 2, the higher A-PRF concentration used, the higher expression of TGF- $\beta 1$ will be released. In odontoblasts, TGF- $\beta 1$ plays a key role in the transcriptional regulation of two noncollagenous proteins, DSPP and DMP-1 [6]. According to Niwa et al. (2018), the mRNA expression level of DSPP is significantly enhanced by TGF- $\beta 1$ in an experimental period of 7 days. These findings suggest that TGF- $\beta 1$ is one of the odontoblast differentiation regulators and could be a useful differentiation marker for odontoblasts [6].

GFs activate signaling sequences required for the proliferation process. After the cell divides into daughter cells and exits the cell cycle, there are several possibilities that occur regarding whether the cell can proliferate, die through the apoptosis process, enter
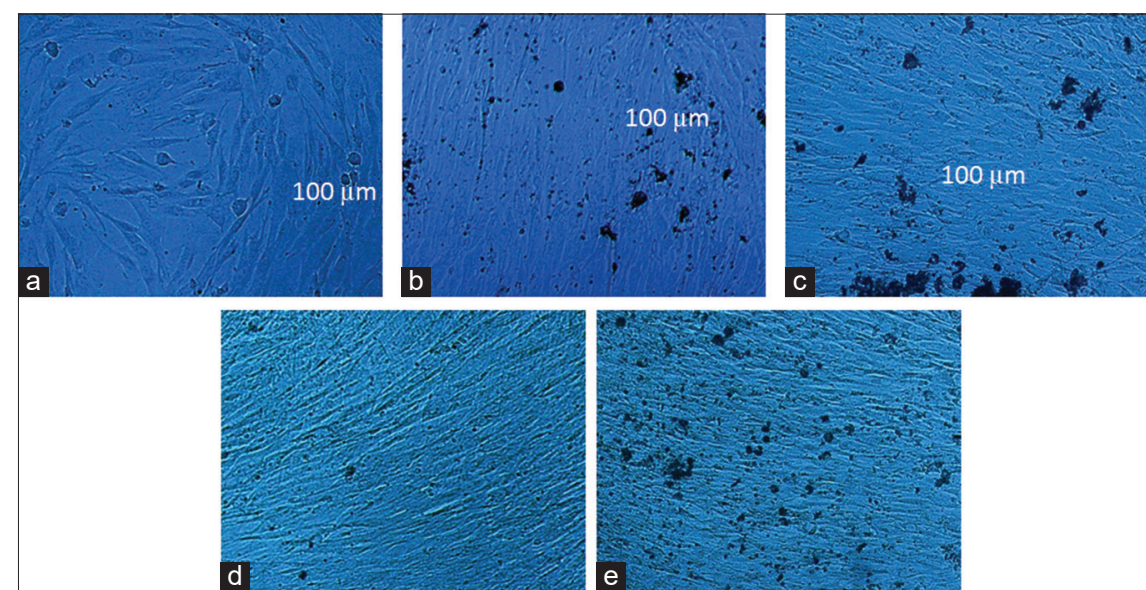

Fig. 1: Microscopic images of human dental pulp stem cells as viewed under the inverted light microscope at $\times 10$; (a) cells after 24-h starvation before treatment (b), $10 \%$ fetal bovine serum as positive control; (c), $1 \%$ advanced platelet-rich fibrin (A-PRF); (d), $5 \%$ A-PRF; (e), 25\% A-PRF (inverted Microscope, Carl Zeiss, UK) 


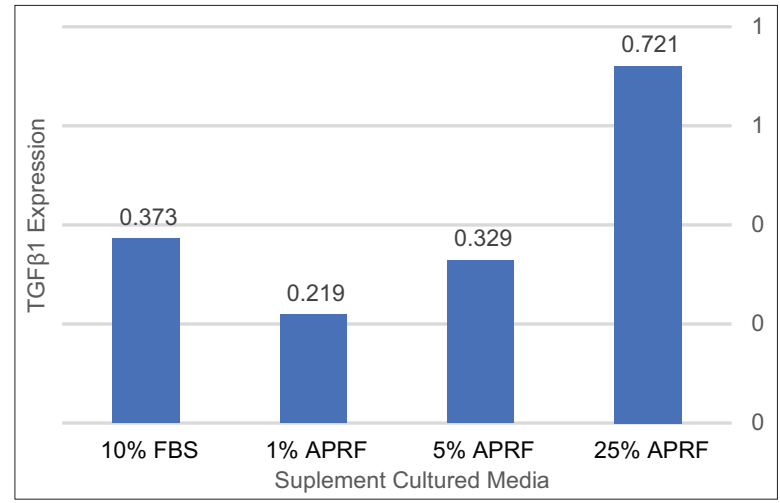

Fig. 2: Mean values of transforming growth factor beta-1 expression $(\mathrm{ng} / \mathrm{ml})$ in various concentrations of advanced platelet-rich fibrin on day 7

Table 1: Analysis of TGF- $\beta 1$ expression ( $\mathrm{ng} / \mathrm{ml})$ in various concentrations of A-PRF on day 7

\begin{tabular}{lllllll}
\hline $\begin{array}{l}\text { Supplement } \\
\text { cultured } \\
\text { media (\%) }\end{array}$ & $\mathbf{n}$ & Mean & SD & Median & Min-Max & p \\
\hline FBS 10 & 3 & 0.373 & 0.228 & 0.378 & $0.349-0.394$ & 0.095 \\
A-PRF 1 & 3 & 0.219 & 0.225 & 0.093 & $0.086-0.479$ & \\
A-PRF 5 & 3 & 0.329 & 0.255 & 0.475 & $0.035-0.479$ & \\
A-PRF 25 & 3 & 0.721 & 0.191 & 0.821 & $0.501-0.843$ & \\
\hline
\end{tabular}

*Kruskal-Wallis test, $\mathrm{p}<0.05$

the senescence phase, or start entering the differentiation phase. Substitution of proliferation into differentiation depends on the presence of proliferative inhibitors and activation of specific cell genes that will form different cells $[14,15]$. DNA-binding protein inhibitors (Id binding), known as protein differentiation inhibitors, have an important role in proliferation till the differentiation shifting process. Myc, which is activated by GFs, can increase Id binding expression, which supports the proliferation process by disabling the cyclindependent kinase inhibitor p16INK4a. TGF- $\beta$ can reduce the number of Id binding sites so that the proliferation process could be inhibited and support the start of the differentiation process. Id binding acts as a differentiation inhibitor by preventing specific transcription factors in a network $[14,15]$.

In this study, the highest expression of TGF- $\beta 1$ was found in $25 \%$ A-PRF culture media supplement, whereas the lowest was observed at $1 \%$ concentration. This is consistent with the results of Bagio et al. (2019) who reported that the highest expression of DSPP in the odontogenic differentiation of hDPSCs was obtained at $1 \%$ A-PRF and the lowest at a concentration of $25 \%$. The presence of TGF- $\beta 1$ in the culture media can stimulate the differentiation process, but if the amount is too high, it can be toxic and inhibit the process of differentiation itself $[5,13,16,17]$. The microscopic images (Fig. 1), the TGF- $\beta 1$ expression analysis (Table 1 ), and the images (Fig. 2 ) indicate sustainable results each explaining that TGF- $\beta 1$ plays an important role in hDPSC differentiation.

\section{CONCLUSION}

The increase of A-PRF concentration correlates with the expression of TGF- $\beta 1$, which modulated the differentiation process of hDPSCs. The $25 \%$ A-PRF group resulted the highest TGF- $\beta 1$ expression among all groups.

\section{ACKNOWLEDGMENT}

We thank our colleagues, Yanni Dirgantara S.Si and Emilia Rahmadaniah Utami, S.Si from ProSTEM Laboratory, and collaborators for their excellent experimental assistance and discussions.

\section{REFERENCES}

1. Hong S, Chen BJ. A comparative evaluation of concentrated growth factor and platelet-rich fibrin on the proliferation, migration, and differentiation of human stem cells of the apical papilla. J Endod 2018;1:977-83.

2. Srivastava S. Current and future perspectives for dentin-pulp tissue engineering-an update. SADJ 2019;74:110-4.

3. Mari-Beffa M, Segura-Egea JJ, Diaz-Cuenca A. Regenerative endodontic procedures: A perspective from stem cell niche biology. J Endod 2017;43:52-62.

4. El Bagdadi K, Kubesch A, Yu X, Al-Maawi S, Orlowska A, Dias A, et al. Reduction of relative centrifugal forces increases growth factor release within solid platelet-rich-fibrin (PRF)-based matrices: A proof of concept of LSCC (low speed centrifugation concept). Eur J Trauma Emerg Surg 2019;45:467-79.

5. Bagio DA, Julianto I, Suprastiwi E, Margono A. Ideal concentration of advanced-platelet rich fibrin (A-PRF) conditioned media for human dental pulp stem cells differentiation. APESB 2019;19:4754.

6. Niwa T, Yamakoshi Y, Yamazaki H, Karakida T, Chiba R, Hu JC, et al. The dynamics of TGF- $\beta$ in dental pulp, odontoblasts and dentin. Sci Rep 2018;8:4450.

7. da Rosa WL, Piva E, da Silva AF. Disclosing the physiology of dental pulp for vital pulp therapy. Int Endod J 2018;51:829-46.

8. Marsa RD, Asrianti D, Margono A. The efficacy of platelet-rich fibrin lysate (PRF-L) for fibroblast cell proliferation. J Int Dent Med Res 2017;10:809-13.

9. He L, Zhong J, Gong Q. Regenerative endodontics by cell homing. Dent Clin N Am 2017;61:143-59.

10. Lin PS, Chang HH, Yeh CY, Chang MC, Chan CP, Kuo HY, et al. Transforming growth factor Beta 1 increases collagen content, and stimulates procollagen I and tissue inhibitor of metalloproteinase-1 production of dental pulp cells: Role of MEK/ERK and activin receptorlike kinase-5/smad signaling. J Formos Med Assoc 2017;116:351-8.

11. Orti V, Collart-Dutilleul PY, Piglionico S, Pall O, Cuisinier F, Panayotov I. Pulp regeneration concepts for non-vital teeth: From tissue engineering to clinical approaches. Tissue Eng Part B Rev 2018;24:419-42.

12. Maniyar N, Sarode GS, Sarode SC, Shah J. Platelet-rich fibrin: A "wonder material" in advanced surgical dentistry. Med J D Y Patil Vidyapeeth 2018;11:287.

13. Margono A, Asrianti D, Meydiawati R. The efficacy of advanced platelet-rich fibrin (A-PRF) on fibroblast cell regeneration. J Int Dent Med Res 2017;10:789-92.

14. Berridge M. Cell Cycle and Proliferation. United Kingdom: Portland Press Limited; 2014.

15. Berridge MJ. Module 8: Development in cell signaling biology. Portland Press Limited 2014;8:1-61.

16. Grafe I, Alexander S, Peterson JR, Snider TN, Levi B, Lee B, et al. TGF-b family signaling in mesenchymal differentiation. Cold Spring Harb Perspect Bio 2018;10:a022202.

17. Morikawa M, Derynck R, Miyazono K. TGF-b and the TGF-b family: Context-dependent roles in cell and tissue physiology. Cold Spring Harb Perspect Biol 2016;8:a021873. 